\title{
Mapping a Cardiomyopathy Locus to Chromosome 3p22-p25
}

Timothy M. Olson* and Mark T. Keating ${ }^{\ddagger \S \mid \uparrow}$

*Division of Pediatric Cardiology, Primary Children’s Medical Center and ${ }^{\ddagger}$ Howard Hughes Medical Institute, ${ }^{\S}$ Eccles Institute of Human Genetics, "Department of Human Genetics, and "Division of Cardiology, University of Utah Health Sciences Center, Salt Lake City,

Utah 84112

\section{Abstract}

Dilated cardiomyopathy (DCM) is a common disorder characterized by cardiac dilation and reduced systolic function. To identify a cardiomyopathy gene, we studied a family with DCM associated with sinus node dysfunction, supraventricular tachyarrhythmias, conduction delay, and stroke. A general linkage approach was used to localize the disease gene in this family. Linkage to D3S2303 was identified with a two-point lod score of 6.09 at a recombination fraction of 0.00 . Haplotype analyses mapped this locus to a $30 \mathrm{cM}$ region of chromosome $3 \mathrm{p} 22-\mathrm{p} 25$, excluding candidate genes encoding a G-protein (GNAI2), calcium channel (CACNL1A2), sodium channel (SCN5A), and inositol triphosphate receptor (ITPR1). These data indicate that a gene causing DCM associated with rhythm and conduction abnormalities is located on chromosome $3 \mathrm{p}$, and represent the first step toward disease gene identification. (J. Clin. Invest. 1996. 97:528-532.) Key words: cardiomyopathy, congestive - heart conduction system - sinoatrial node • arrhythmia $\cdot$ linkage (genetics)

\section{Introduction}

Dilated cardiomyopathy $(\mathrm{DCM})^{1}$ is a disorder characterized by cardiac dilation and reduced systolic function and represents a final common pathway of a heterogeneous group of inherited and acquired disorders. Idiopathic DCM accounts for approximately one-half of all DCM cases (1) and, by definition, excludes DCM caused by myocarditis, coronary artery disease, systemic diseases, and myocardial toxins. Idiopathic DCM is relatively common (prevalence 36.5/100,000); it accounts for more than 10,000 deaths in the United States annually and is the primary indication for cardiac transplantation (2). The final outcome of medical treatment is variable in children and poor in adults $(1,3)$.

Address correspondence to Timothy M. Olson, M.D., Division of Pediatric Cardiology, Primary Children's Medical Center, University of Utah, 100 North Medical Drive, Salt Lake City, UT 84113. Phone: 801-588-2600; FAX 801-588-2612.

Received for publication 28 August 1995 and in revised form 6 October 1995.

1. Abbreviations used in this paper: CACNL1A2, calcium channel, $\mathrm{L}$ type, alpha-1 polypeptide; DCM, dilated cardiomyopathy; GNAI2, guanine nucleotide-binding protein ( $\mathrm{G}$ protein); ITPR1, inositol 1,4,5-triphosphate receptor, type 1 ; SCN5A, sodium channel, voltagegated, type V, alpha polypeptide; SSCP, single-strand conformation polymorphism.

J. Clin. Invest.

(C) The American Society for Clinical Investigation, Inc.

0021-9738/96/01/528/05 \$2.00

Volume 97, Number 2, January 1996, 528-532
The prevalence of familial disease is $\sim 20-25 \%$ for idiopathic DCM $(4,5)$, indicating that single gene defects are important in the pathogenesis of this disorder. However, with the exception of rare cases resulting from mutations in dystrophin $(6,7)$ or mitochondrial genes $(8)$, the molecular basis of DCM is unknown. Genetic analyses, however, have been complicated by the scarcity of large DCM families. In this study, we ascertained and phenotypically characterized a large family with DCM associated with abnormal cardiac automaticity and conduction. We then used genetic linkage analyses to localize a novel DCM gene to the short arm of chromosome 3 .

\section{Methods}

Phenotypic characterization. The clinical description of a portion of the family used in this study (kindred 1500) was reported previously by Greenlee and colleagues (9). Phenotypic characterization was updated as additional clinical information became available and expanded to include additional family members. Affected individuals were more likely to seek medical attention and participate in the study. By contrast, branches of the pedigree without obvious disease were not investigated because these individuals would provide no useful information for linkage analysis. Family members were clinically evaluated by a medical history, physical examination, two dimensional and M-mode echocardiography, and standard and/or continuous ambulatory electrocardiography. Cardiac chamber dilation

Table I. Quantitative Phenotyping in Kindred 1500

\begin{tabular}{lc}
\hline \multicolumn{1}{c}{ Clinical findings } & Points \\
\hline Asymptomatic sinus bradycardia (heart rate $\leq 50)$ & 1 \\
Incomplete bundle branch block $\leq$ age 30 & 1 \\
$\quad($ QRS interval 0.10-0.12 s) & 2 \\
Symptomatic supraventricular tachycardia $\leq$ age 30 & 2 \\
First degree AV block $\leq$ age 30 (PR interval $>0.22 \mathrm{~s})$ & 2 \\
Clinical heart failure $\leq$ age 55 & 2 \\
Echocardiographic atrial dilation & 2 \\
Echocardiographic ventricular dilation & \\
Left ventricular systolic dysfunction & 3 \\
$\quad$ (shortening fraction $<28 \%)$ & 3 \\
Complete bundle branch block $\leq$ age 30 & 4 \\
$\quad$ QRS interval $>0.12$ s) & \\
Symptomatic second degree AV block $\leq$ age 30 & 4 \\
Symptomatic sinus node dysfunction & 5 \\
$\quad$ (sinus pauses or arrest) &
\end{tabular}

Phenotypic features of the disease in kindred 1500 were characterized by history, electrocardiography, and echocardiography. A point value was assigned to each clinical feature and affection status was determined by the summed points for each individual: 0 points $=$ unaffected, 1-4 points $=$ uncertain, $\geq 5$ points $=$ affected. Normal values: heart rate, 60-100 bpm; QRS interval, $<0.10 \mathrm{~s}$; PR interval, 0.12-0.20 s; shortening fraction, $28-45 \%(11,13)$. 

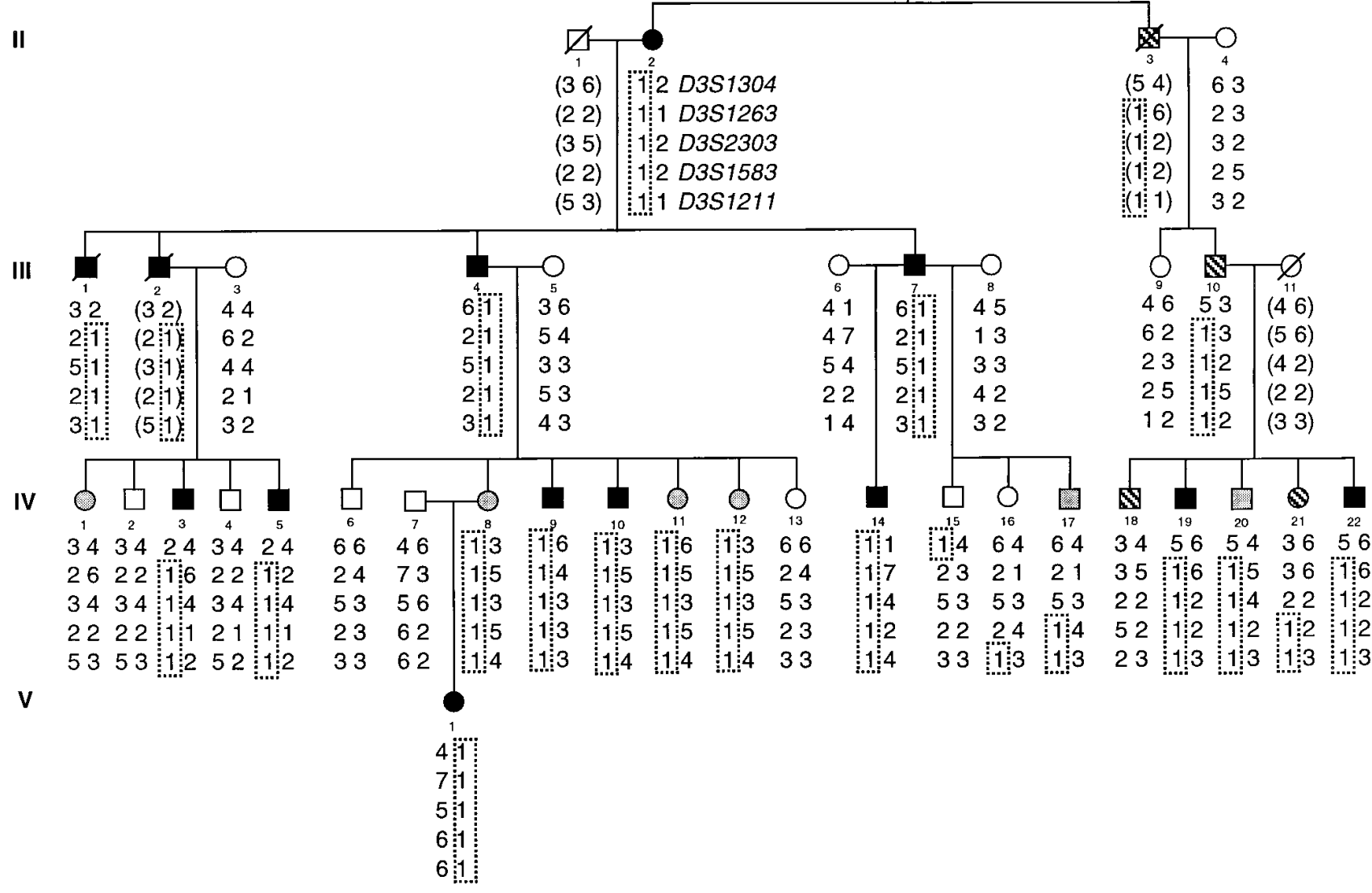

Figure 1. Pedigree structure and haplotypes for kindred 1500 with DCM associated with abnormal cardiac automaticity and conduction. Affected individuals are indicated by filled circles (females) or squares (males). Symbols are empty for unaffected individuals, shaded for individuals with uncertain phenotypes, and cross-hatched for individuals with no phenotypic data. Diagonal lines indicate deceased individuals. Genotypes for D3S1304, D3S1263, D3S2303, D3S1583, and D3S1211 (telomere to centromere) are shown. Inferred genotypes are shown in parentheses. The disease-associated haplotype $(1,1,1,1,1)$ is indicated by boxes.

was defined as cross-sectional dimension $>95$ th percentile for body surface area and left ventricular dysfunction was defined as a shortening fraction $<28 \%$ by M-mode echocardiographic measurements (10-12). Low normal left ventricular systolic function was defined as a shortening fraction of $28-30 \%$. Resting heart rate was determined while awake. Definition of rhythm and conduction abnormalities was based on established criteria (13). Age criteria were also used for point assignment, as indicated in Table I. The conservative, quantitative approach to phenotypic assignment we employed resulted in several individuals being classified as uncertain. This method avoids misclassification but may result in reduced statistical power. To avoid bias, phenotypic data were interpreted without knowledge of genotype.

Genotypic analyses. Whole blood was collected from consenting family members. Genomic DNA was extracted from the sample and EBV-transformed lymphoblastoid cell lines (14) were established. Sequences of PCR-based microsatellite markers were obtained from the Genome Data Base. PCR genotyping was performed with modifications of the method described by Weber and May (15). PCR was carried out with $25 \mathrm{ng}$ of DNA in a final volume of $10 \mu \mathrm{l}$ using a Perkin-Elmer Cetus 9600 thermocycler. Amplification conditions were $94^{\circ} \mathrm{C}$ for $5 \mathrm{~min}$, followed by 30 cycles of $94^{\circ} \mathrm{C}$ for $30 \mathrm{~s}, 55^{\circ} \mathrm{C}$ for $30 \mathrm{~s}$, and $72^{\circ} \mathrm{C}$ for $30 \mathrm{~s}$, followed by $72^{\circ} \mathrm{C}$ for $10 \mathrm{~min} .10 \mu \mathrm{l}$ of formamide dye was added to each reaction, and samples were denatured at $94^{\circ} \mathrm{C}$ for $3 \mathrm{~min}$ and held on ice. $2 \mu \mathrm{l}$ were loaded on a $6 \%$ denaturing polyacrylamide gel and DNA fragments were resolved by electrophoresis.
Gels were dried and exposed to X-ray film for 1-2 d at room temperature. For SSCP (16) analyses, primer pairs were designed from noncoding genomic sequence in the GenBank and EMBL databanks, accessed using IntelliGenetics software. Genomic DNA was amplified as described above. Reactions $(10 \mu \mathrm{l})$ were diluted with $50 \mu \mathrm{l}$ of $0.1 \%$ SDS, $1 \mathrm{mM}$ EDTA, and $50 \mu \mathrm{l}$ of $95 \%$ formamide dye. Diluted products were denatured by heating at $94^{\circ} \mathrm{C}$ for $10 \mathrm{~min}$, and $3 \mu \mathrm{l}$ of each sample was separated by electrophoresis on $10 \%$ nondenaturing polyacrylamide gels (50:1 acrylamide:bisacrylamide), with or without $10 \%$ glycerol, at $4^{\circ} \mathrm{C}$. Electrophoresis was carried out at $40 \mathrm{~W}$ for 4 $12 \mathrm{~h}$.

Linkage analyses. To avoid bias, all genotypes were scored without knowledge of phenotypic data. For linkage analyses, penetrance was set at 0.95 and the disease allele frequency was assumed to be 0.001 and equal between males and females. Because the prevalence of idiopathic DCM is $\sim 0.00037$ (2) and DCM with abnormal automaticity and conduction is less prevalent, the sporadic (phenocopy) rate of disease was set at zero. Microsatellite allele frequencies were set to equal $(1 / \mathrm{n})$. The LINKAGE version 5.1 software package was used to perform pairwise (MLINK) linkage analyses for all individuals who were genotyped (17). The $\sim 90 \%$ confidence limits were calculated using the "1 lod down" method (18). Multipoint linkage analyses were performed with the FASTLINK version of LINKMAP $(19,20)$. Marker loci order and intermarker distances were based on existing linkage maps $(21,22)$ and haplotype analyses in kindred 1500 . To minimize computational constraints, alleles were recoded to limit the 


\begin{tabular}{|c|c|c|c|c|c|c|c|c|c|c|c|c|}
\hline \multirow{2}{*}{$\begin{array}{l}\text { Pedigree } \\
\text { number }\end{array}$} & \multirow[b]{2}{*}{ Age } & \multirow[b]{2}{*}{ HR } & \multirow[b]{2}{*}{ Tachy } & \multirow{2}{*}{$\begin{array}{c}\text { PR } \\
\text { interval }\end{array}$} & \multirow{2}{*}{$\begin{array}{l}\text { QRS } \\
\text { interval }\end{array}$} & \multirow[b]{2}{*}{ Stroke } & \multirow[b]{2}{*}{ CHF } & \multicolumn{2}{|c|}{ Dilated } & \multirow[b]{2}{*}{$\mathrm{SF}$} & \multirow{2}{*}{$\begin{array}{l}\text { Total } \\
\text { points }\end{array}$} & \multirow{2}{*}{$\begin{array}{l}\text { Affection } \\
\text { status }\end{array}$} \\
\hline & & & & & & & & Atria & Ventricles & & & \\
\hline & & bpm & & $s$ & $s$ & & & & & $\%$ & & \\
\hline II-2 & 88 & Ind & $\mathbf{A F}$ & Ind & 0.07 & - & - & B & $\mathbf{R}$ & $>28^{*}$ & 6 & A \\
\hline III-1 & 62 & 76 & - & 0.24 & 0.09 & - & - & $\mathbf{L}$ & - & 24 & 5 & A \\
\hline III-2 & 60 & SND & $\mathbf{A F}$ & Ind & 0.14 (L) & $37 \mathbf{y r}$ & $54 \mathrm{yr}$ & B & B & $<\mathbf{2 8}^{*}$ & 23 & A \\
\hline III-4 & 58 & SND & $\mathbf{A F}$ & Ind & 0.13 (R) & - & $52 \mathrm{yr}$ & B & B & 26 & 18 & A \\
\hline III-7 & 47 & Ind & $\mathbf{A F}$ & Ind & 0.09 & - & $50 \mathrm{yr}$ & B & $\mathbf{R}$ & 23 & 11 & A \\
\hline III-9 & 68 & 79 & - & 0.13 & 0.08 & - & - & - & - & 33 & 0 & $\mathrm{~N}$ \\
\hline IV-1 & 37 & 63 & SVT $^{\dot{t}}$ & 0.18 & 0.08 & - & - & - & - & $>28^{*}$ & 2 & $\mathrm{U}$ \\
\hline IV-2 & 36 & 61 & - & 0.14 & 0.09 & - & - & - & - & $>28 *$ & 0 & $\mathrm{~N}$ \\
\hline IV-3 & 31 & 56 & $\mathbf{A F}$ & 0.24 & 0.11 (IR) & - & - & - & - & 41 & 5 & A \\
\hline IV-4 & 28 & 71 & - & 0.20 & 0.08 & - & - & - & - & $>28 *$ & 0 & $\mathrm{~N}$ \\
\hline IV-5 & 22 & SND & - & 0.24 & 0.08 & $33 \mathrm{yr}$ & - & $\mathbf{L}$ & - & 33 & 13 & A \\
\hline IV-6 & 34 & 60 & - & 0.12 & 0.09 & - & - & - & - & 38 & 0 & $\mathrm{~N}$ \\
\hline IV-8 & 31 & 46 & - & 0.18 & 0.10 (IR) & - & - & - & - & (29) & 2 & $\mathrm{U}$ \\
\hline IV-9 & 29 & SND & $\mathbf{A F}$ & $2^{\circ} \mathbf{A V B}$ & 0.10 (IR) & $29 \mathrm{yr}$ & $29 \mathrm{yr}$ & B & B & $37^{\S}$ & 22 & A \\
\hline IV-10 & 37 & SND & SVT & 0.18 & 0.10 (IR) & - & - & - & - & (30) & 7 & A \\
\hline IV-11 & 24 & 36 & - & 0.19 & 0.09 & - & - & - & - & (30) & 1 & $\mathrm{U}$ \\
\hline IV-12 & 31 & 47 & - & 0.16 & 0.10 (IR) & - & - & - & - & 35 & 2 & $\mathrm{U}$ \\
\hline IV-13 & 25 & 86 & - & 0.14 & 0.06 & - & - & - & - & 34 & 0 & $\mathrm{~N}$ \\
\hline IV-14 & 10 & SND & - & 0.24 & 0.10 (IL) & - & - & - & - & (28) & 7 & A \\
\hline IV-15 & 32 & 59 & - & 0.14 & 0.10 (IR) & - & - & - & - & $>28 *$ & 0 & $\mathrm{~N}$ \\
\hline IV-16 & 29 & 92 & - & 0.14 & 0.09 & - & - & - & - & 41 & 0 & $\mathrm{~N}$ \\
\hline IV-17 & 22 & 75 & - & 0.19 & 0.10 (IR) & - & - & - & - & 33 & 1 & $\mathrm{U}$ \\
\hline IV-19 & 26 & SND & $\mathbf{A F}$ & $2^{\circ} \mathrm{AVB}$ & 0.11 (IR) & - & - & ND" & $\mathrm{ND}^{\|}$ & ND & 11 & A \\
\hline IV-20 & 11 & 50 & - & 0.16 & 0.11 (IR) & - & - & ND & ND & ND & 2 & $\mathrm{U}$ \\
\hline IV-22 & 21 & SND & - & $2^{\circ} \mathbf{A V B}$ & $0.13(\mathrm{R})$ & - & - & - & - & 31 & 11 & A \\
\hline V-1 & 6 & 99 & PJRT & $2^{\circ} \mathbf{A V B}$ & 0.07 & - & - & $\mathbf{L}$ & - & 34 & 8 & A \\
\hline
\end{tabular}

Abnormal values are indicated in bold type. Phenotypic data were unavailable for individuals I-1, I-2, II-3, III-10, IV-18, and IV-21, so these individuals were classified as uncertain. There was no history of consanguinity and spouses were classified as unaffected. *Left ventricular function was assessed by two-dimensional echocardiography but SF was not quantified by M-mode. ${ }^{\ddagger}$ Had SVT once during pregnancy. ${ }^{\S}$ On digitalis therapy. "Individuals IV-19 and IV-20 were unavailable for echocardiography, but IV-19 had cardiomegaly on chest radiographs. Age, age at most recent evaluation; $H R$, sinus heart rate; $S N D$, sinus node dysfunction; Ind, indeterminate due to chronic $A F$; Tachy, tachyarrhythmias; $A F$, atrial flutter/fibrillation; $S V T$, supraventricular tachycardia; PJRT, paroxysmal junctional reciprocating tachycardia; $2^{\circ} \mathrm{AVB}$, second degree atrioventricular block; $(R)$, right bundle branch block; $(L)$, left bundle branch block; $(I)$, incomplete; $C H F$, clinical heart failure; $B$, bilateral; $L$, left; $R$, right; $N D$, not determined; $S F$, shortening fraction (low normal SF indicated by parentheses); $A$, affected; $N$, not affected; $U$, uncertain; -, no abnormality.

number of alleles per marker, without loss of informativeness. In addition, seven individuals with an uncertain phenotype (IV-1, IV-11, IV-12, IV-17, IV-18, IV-20, and IV-21) were excluded from multipoint analyses.

\section{Results}

To identify a gene that causes dilated cardiomyopathy, we studied a family (kindred 1500) of German and Swiss ancestry with DCM associated with abnormal cardiac automaticity and conduction (Fig. 1). Typically, disease manifestations begin in adolescence with the onset of sinus node dysfunction, ranging from asymptomatic sinus bradycardia to symptomatic sinus pauses and arrest. Some individuals present with junctional bradycardia or supraventricular tachyarrhythmias, usually atrial flutter or fibrillation. The disease progresses to involve the AV node and His-Purkinje conduction system, manifest by AV and bundle branch block. Finally, the natural history is characterized by dilation of atria and ventricles with left ventricular systolic dysfunction and clinical heart failure.
The disease phenotype in kindred 1500 segregates as an autosomal dominant trait with high penetrance. Phenotypic expression was variable, and one individual (III-1) demonstrated only left atrial dilation and left ventricular dysfunction. Because of the complex phenotype, a quantitative scoring system was used for phenotypic assignment (Table I). The phenotypic characteristics and assignment for each individual are described in Table II.

A genome-wide linkage approach was used to localize the disease gene in kindred 1500. Genotypes for 105 highly polymorphic microsatellite markers were scored before linkage was identified, excluding $\sim 50 \%$ of the genome (lod score $\leq-2$ ). Linkage to a cardiomyopathy locus on chromosome 1 (23) was also excluded. Ultimately, we identified complete linkage between the disease phenotype and a tetranucleotide repeat marker on chromosome 3, D3S2303 (Fig. 1 and Table III). The maximum two-point lod score was 6.09 at a recombination fraction of 0.00 ( $95 \%$ penetrance).

Haplotype analyses with markers adjacent to D3S2303 localized the disease gene to a $30 \mathrm{cM}$ region of chromosome 
Table III. Two-Point Lod Scores for Kindred 1500 with Chromosome 3 Markers

\begin{tabular}{lrrrrrrr}
\hline & \multicolumn{7}{c}{ Recombination Fraction } \\
\hline Locus & 0.00 & 0.01 & 0.05 & 0.10 & 0.20 & 0.30 & 0.40 \\
D3S1304 & -1.11 & 0.23 & 1.30 & 1.83 & 1.99 & 1.62 & 0.95 \\
D3S1263 & 4.91 & 4.83 & 4.51 & 4.08 & 3.18 & 2.21 & 1.16 \\
D3S2303 & 6.09 & 5.99 & 5.59 & 5.07 & 3.96 & 2.72 & 1.35 \\
D3S1583 & 5.32 & 5.23 & 4.85 & 4.35 & 3.29 & 2.11 & 0.86 \\
D3S1211 & 3.20 & 3.21 & 3.16 & 2.99 & 2.48 & 1.81 & 0.99 \\
& & & & & & & \\
\hline
\end{tabular}

$Z_{\max }=6.09$, recombination fraction $=0.00,90 \%$ confidence limits: (0-0.098) Two-point lod scores were calculated assuming autosomal dominant inheritance, disease allele frequency of 0.001 , equal male and female recombination frequencies, and $95 \%$ penetrance. When penetrance was varied from 60 to $100 \%$ for $D 3 \$ 2303$, lod scores at a recombination fraction of 0.00 ranged from 5.20 to 6.24 , respectively.

3p22-p25. The flanking markers were D3S1304 and D3S1211 (Fig. 1). Recombination events were identified within this interval in two individuals (IV-17 and IV-21), but both were classified as phenotypically uncertain. Results of multipoint analyses supported results of the two-point and haplotype analyses. The maximum lod score was obtained with marker D3S2303 $\left(Z_{\max }=6.09\right.$ at a recombination fraction of 0.00$)$, as shown in Fig. 2.

17 of 30 at-risk, phenotypically characterized individuals inherit the disease-associated allele of D3S2303. Disease penetrance is age-dependent and incomplete and no single trait was present in all individuals. Sinus bradycardia or sinus node dysfunction best distinguish disease-allele carriers (12/17) and non-carriers (0/9), followed by bundle branch block, cardiac chamber dilation, and supraventricular tachyarrhythmia. Because phenotyping was based on strict clinical criteria, only two individuals who do not inherit the disease allele have a quantitative score greater than zero; individuals IV-1 and IV17 had scores of 2 and 1 , respectively.

Several candidate genes map to this region of chromosome 3 (Genome Data Base), including a G-protein (GNAI2), calcium channel (CACNL1A2), sodium channel (SCN5A), and inositol triphosphate receptor (ITPR1). We identified polymorphisms in noncoding regions of these genes by SSCP(16) analyses and used these markers for genetic linkage analyses. In addition, an SSCP marker was identified in an unmapped candidate gene encoding a gap junction protein, connexin 45 (24). Recombination between the disease phenotype and these genes was identified in all cases (data not shown). These data exclude the candidacy of GNAI2, CACNL1A2, SCN5A, ITPR1, and connexin 45 in this family.

\section{Discussion}

We have localized a dilated cardiomyopathy gene to the short arm of chromosome 3, near D3S2303. The identity of this gene is not yet known, but we have excluded several candidate genes, including GNAI2, CACNL1A2, SCN5A, ITPR1, and connexin 45. Identification of this DCM locus represents a step toward molecular definition of this life-threatening disorder.

The clinical features of idiopathic DCM have been recently reviewed (25). Patients with DCM typically present with heart failure between the ages of 20 and $50 \mathrm{yr}$. Conduction and rhythm abnormalities are common in DCM, particularly with advanced myocardial dysfunction. Conduction abnormalities, usually first degree AV block and left bundle branch block, occur in $80 \%$ of patients. Atrial tachyarrhythmias, usually atrial flutter or fibrillation, occur in $20 \%$ of cases. By contrast, DCM in kindred 1500 is preceded by arrhythmias and conduction abnormalities, typically AV block and right bundle branch block. Abnormal automaticity (sinus bradycardia and sinus node dysfunction) is also an early manifestation of disease in this family. Sinus node disease has been reported in $6 \%$ of patients with DCM $(26,27)$. However, the prevalence of DCM associ-

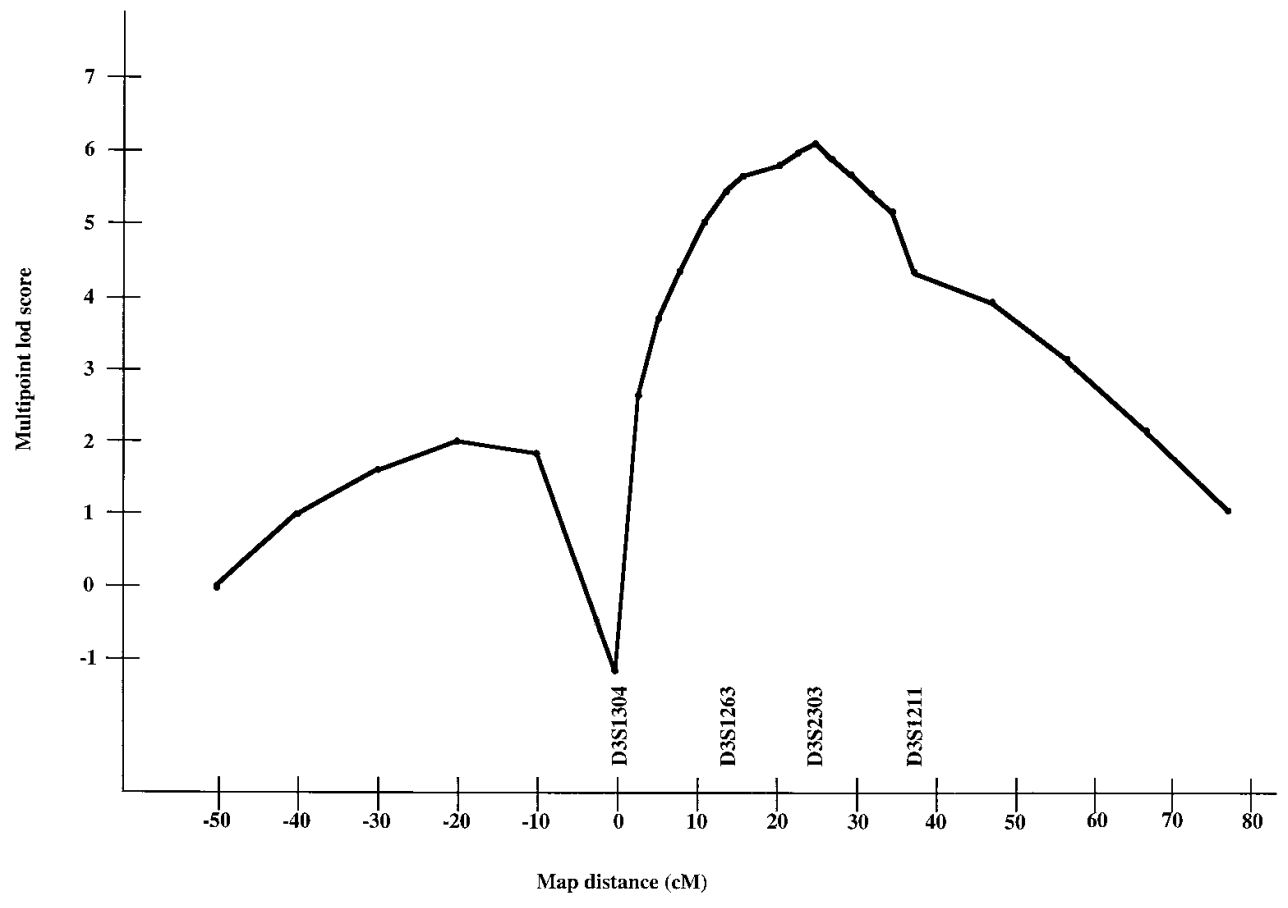

Figure 2. Five-point linkage analyses for kindred 1500 . The multipoint lod score of the disease locus is plotted against genetic distance in a fixed map of chromosome 3 markers. 
ated with sinus node disease may be underestimated because heart failure is later in onset in this subgroup of patients.

The relative importance of this DCM locus is not yet known. Because mortality in idiopathic DCM is high (5-yr mortality $=40-80 \%)(28)$ and penetrance is incomplete, DCM families suitable for linkage analysis are rare. Linkage studies of a family with a phenotype very similar to kindred 1500 (DCM, sinus bradycardia, conduction delay, and atrial fibrillation) led to identification of a DCM locus on chromosome 1 (23), but we excluded this locus in kindred 1500. Our findings, therefore, indicate that DCM is genetically heterogeneous. Once these DCM genes are identified, their relative importance in familial and sporadic cardiomyopathy will be determined.

In summary, we have identified a cardiomyopathy locus on chromosome 3p22-p25 associated with abnormal cardiac automaticity and conduction. Future experiments will focus on expanding kindred 1500 for refined genetic mapping and identification of additional candidate genes. Identification and characterization of this cardiomyopathy gene will improve our understanding of DCM and may lead to new therapeutic strategies.

\section{Acknowledgments}

We gratefully acknowledge the family members who participated in this study. We thank Amanda Ewart, Sally Sharp, Donald Atkinson, Yin-Shan Tai, Qing Wang, Changan Jiang, Jeffrey Anderson, Mark Leppert, Garth Orsmond, and Virginia Michels for their help and advice.

This work was supported by National Heart, Lung, and Blood Institute grant HL-53773-01, by Public Health Services Research Grant M01-RR00064 from the National Center for Research Resources, the Technology Access Section of the Utah Genome Center, and by the American Heart Association.

\section{References}

1. Kasper, E. K., W. R. P. Agema, G. M. Hutchins, J. W. Deckers, J. M. Hare, and K. L. Baughman. 1994. The causes of dilated cardiomyopathy: a clinicopathologic review of 673 consecutive patients. J. Am. Coll. Cardiol. 23:586590.

2. Manolio, T. A., K. L. Baughman, R. Rodeheffer, T. A. Pearson, J. D. Bristow, V. V. Michels, W. H. Abelmann, and W. R. Harlan. 1992. Prevalence and etiology of idiopathic dilated cardiomyopathy (Summary of a national heart, lung, and blood institute workshop). Am. J. Cardiol. 69:1458-1466.

3. Wiles, H. B., P. D. McArthur, A. B. Taylor, P. C. Gillete, D. A. Fyfe, J. P. Matthews, and L. W. Shelton. 1991. Prognostic features of children with idiopathic dilated cardiomyopathy. Am. J. Cardiol. 68:1372-1376.

4. Michels, V. V., P. P. Moll, F. A. Miller, A. J. Tajik, J. S. Chu, D. J. Driscoll, J. C. Burnett, R. J. Rodeheffer, J. H. Chesebro, and H. D. Tazelaar. 1992. The frequency of familial dilated cardiomyopathy in a series of patients with idiopathic dilated cardiomyopathy. N. Engl. J. Med. 326:77-82.

5. Keeling, P. J., Y. Gang, G. Smith, H. Seo, S. E. Bent, V. Murday, A. L. P. Cafario, and W. J. McKenna. 1995. Familial dilated cardiomyopathy in the United Kingdom. Br. Heart J. 73:417-421.

6. Towbin, J. A., J. F. Hejtmancik, P. Brink, B. Gelb, X. M. Zhu, J. S. Chamberlain, E. R. McCabe, and M. Swift. 1993. X-linked dilated cardiomyo- pathy. Molecular genetic evidence of linkage to the Duchenne muscular dystrophy (dystrophin) gene at the Xp21 locus. Circulation. 87:1854-1865.

7. Muntoni, F., M. Cau, A. Ganau, R. Congiu, G. Arvedi, A. Mateddu, M. G. Marrosu, C. Cianchetti, G. Realdi, A. Cao, and M. A. Melis. 1993. Deletion of the dystrophin muscle-promoter region associated with $\mathrm{x}$-linked dilated cardiomyopathy. N. Engl. J. Med. 329:921-925.

8. Zeviani, M., C. Gellera, C. Antozzi, M. Rimoldi, L. Morandi, F. Villani, V. Tiranti, and S. DiDonato. 1991. Maternally inherited myopathy and cardiomyopathy: Association with mutation in mitochondrial DNA tRNA(Leu) (UUR). Lancet. 338:143-147.

9. Greenlee, P. R., J. L. Anderson, J. R. Lutz, A. E. Lindsay, and A. D. Hagan. 1986. Familial automaticity-conduction disorder with associated cardiomyopathy. West. J. Med. 144:33-41.

10. Gardin, J. M., W. L. Henry, D. D. Savage, J. H. Ware, C. Burn, and J. S Borer. 1979. Echocardiographic measurements in normal subjects: evaluation of an adult population without clinically apparent heart disease. J. Clin. Ultrasound. 7:439-447.

11. Henry, W. L., J. Ware, J. M. Gardin, S. I. Hepner, J. McKay, and M. Weiner. 1978. Echocardiographic measurements in normal subjects: growthrelated changes that occur between infancy and early adulthood. Circulation. 57:278-285.

12. Felner, J. M., and R. P. Martin. 1994. The echocardiogram. In The Heart. J. W. Hurst, editor. McGraw-Hill, Inc., New York. 375-422.

13. Goldman, M. J. 1986. Review of the normal electrocardiogram \& common abnormalities. In Principles of clinical electrocardiography. Lange Medical Publications, Los Altos, California. 421-428.

14. Roder, J. C., S. P. Cole, and D. Kozbor. 1986. The EBV-hybridoma technique. Methods Enzymol. 121:140-168.

15. Weber, J. L., and P. E. May. 1989. Abundant class of human DNA polymorphisms which can be typed using the polymerase chain reaction. Am. J. Hum. Genet. 44:388-396.

16. Orita, M., H. Iwahana, H. Kanazawa, and T. Sekiya. 1989. Detection of polymorphisms of human DNA by gel electrophoresis as single strand conformation polymorphisms. Proc. Natl. Acad. Sci. USA. 86: 2766-2770.

17. Lathrop, G. M., J. M. Lalouel, C. Julier, and J. Ott. 1985. Multilocus linkage analysis in humans: detection of linkage and estimation of recombination. Am. J. Hum. Genet. 37:482-498.

18. Conneally, J. H., J. H. Edwards, K. K. Kidd, J. M. Lalouel, N. E. Morton, J. Ott, and R. White. 1985. Report of the committee on methods of linkage analysis and reporting. Cytogenet. Cell Genet. 40:356-359.

19. Cottingham, R. W., R. M. Idury, and A. A. Schaffer. 1993. Faster sequential genetic linkage computations. Am. J. Hum. Genet. 53:252-263.

20. Schaffer, A. A., S. K. Gupta, K. Shriram, and R. W. Cottingham. 1994. Avoiding recomputation in genetic linkage analysis. Human Heredity. 44:225237.

21. Smith, D. I., T. W. Glover, R. Gemmill, H. Drabkin, P. O'Connell, and S.L. Naylor. 1995. Report of the fifth international workshop on human chromosome 3 mapping 1994. Cytogenet. Cell. Genet. 68:125-146.

22. The Utah Marker Development Group. 1995. A collection of ordered tetranucleotide-repeat markers from the human genome. Am. J. Hum. Genet. 57:619-628.

23. Kass, S., C. MacRae, H. L. Graber, E. A. Sparks, D. McNamara, H. Boudoulas, C. T. Basson, P. B. Baker, R. J. Cody, M. C. Fishman, N. Cox, A. Kong, C. F. Wolley, J. G. Seidman, and C. E. Seidman. 1994. A gene that causes conduction system disease and dilated cardiomyopathy maps to chromosome 1p11q1. Nature Genet. 7:546-551.

24. Kanter, H. L., J. E. Saffitz, and E. C. Beyer. 1994. Molecular cloning of two human cardiac gap junction proteins, connexin40 and connexin45. J. Mol. Cell. Cardiol. 26:861-868.

25. Dec, G. W., and V. Fuster. 1994. Idiopathic dilated cardiomyopathy. New Engl. J. Med. 331:1564-1575.

26. Ando, S., S. Koyanagi, K. Muramatsu, R. Itaya, A. Takeshita, and M. Nakamura. 1991. Clinical characteristics of patients with dilated cardiomyopathy and bradyarrhythmias. J. Cardiol. 21:53-59.

27. Huang, J., C. Y. Xie, X. Q. Kong, M. Z. Long, M. X. Qiang, W. Z. Ma and J. L. Wang. 1994. Prevalence of arrhythmias in patients with idiopathic dilated cardiomyopathy. Chin. Med. J. (Engl. Ed.). 107:176-180.

28. Gilbert, E. M. and M. R. Bristow. 1994. Idiopathic dilated cardiomyopathy. In The Heart. J.W. Hurst, editor. McGraw-Hill, Inc., New York. 16091619. 